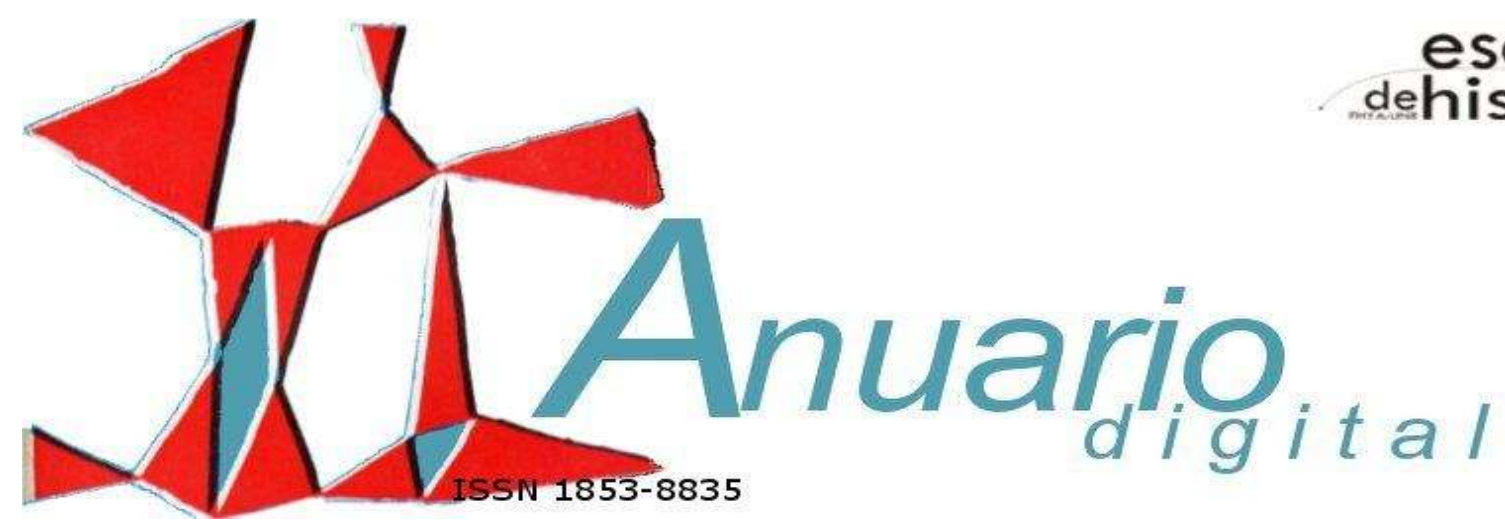

\title{
EL DISPOSITIVO DE MOVILIDAD \\ MICHEL FOUCAULT Y EL PROBLEMA DE LA CIUDAD. BOGOTÁ 1910-1930
}

SANTIAGO CASTRO-GÓMEZ*

Universidad Javierana-Instituto Pensar (Bogotá Colombia);

scastro@javeriana.edu.co

A partir de de Seguridad, Territorio y Población de Michel Foucault, el artículo estudia la construcción de los dispositivos urbanos de movilidad. Los intentos de acoplamiento de Bogotá a la modernidad urbana y capitalista son analizados empleando la "caja de herramientas" foucaultiana. La planificación, la aceleración de los medios de transporte y comunicación, las técnicas para el gobierno de las clases subalternas y la construcción de un medio eficaz para la movilización de los afectos y deseos contribuyeron a la fabricación del capitalismo, la movilidad y la biopolítica en Bogotá en los primeros treinta años del siglo XX.

Palabras clave: Dispositivo de Movilidad - Capitalismo - Foucault - Urbanismo - Modernización

\footnotetext{
*Profesor e Investigador en la Pontificia Universidad Javierana y del Instituto Pensar.
} 
MOBILITY DEVICE. MICHEL FOUCAULT AND THE PROBLEM OF THE CITY. BOGOTÁ 1910-1930

In Territory, security and population Foucault made an analysis about the construction of urban mobility devices. Form these arguments; the present article studies the formation of capitalism urban modernity in Bogota (Colombia). The city planning, accelerating transportation and communication, governmental techniques of subaltern classes and the mobilization of affections and desires collaborated in the production of capitalism, mobility and biopolitics in the early twenty century.

Key words: Mobility Device - Capitalism - Foucault - Urbanism - Modernization

\section{Introducción}

Foucault solía decir a sus estudiantes que podían hacer uso de su obra como si se tratase de una "caja de herramientas". Usar sus conceptos como si se tratase de martillos, tuercas, llaves, metros y puntillas capaces de construir otros universos discursivos, diferentes en todo caso a los ya presentados por el maestro. En vísperas de cumplirse treinta años de su muerte, muchos de quienes hemos recibido esa influencia rendimos homenaje al creador de estas herramientas. Algunas de esas recapitulaciones se enfocan sobre las herramientas en sí mismas, analizando algunos de sus interesantes desafíos teóricos; otras, como es mi caso, explorarán, más bien, el uso que puede hacerse de esas herramientas para la investigación de problemas concernientes a la sociedad y la ciudad colombiana. Y aunque no ha sido mi costumbre escenificar teóricamente a los autores que utilizo para mis investigaciones sobre la historia de Colombia, en esta ocasión hablaré de Foucault y de la importancia que ha tenido su obra para mi propio quehacer académico. Me referiré en particular a sus reflexiones sobre el movimiento y la ciudad, plasmadas en las lecciones de 1977-1978 tituladas Seguridad, territorio, Población. ${ }^{1}$ Quisiera mostrar cómo sus ideas en torno a los dispositivos de seguridad han resultado fructíferas para mí a la hora de investigar un problema concreto: la movilidad urbana en una ciudad como Bogotá hacia comienzos del siglo XX.

Dividiré, pues, mi argumentación en dos secciones. La primera se centrará en los dispositivos de seguridad y en el modo en que Foucault hace uso de este concepto para analizar el problema de las ciudades modernas a partir del siglo XVIII. La segunda se concentrará en el uso que he hecho de estos

${ }^{1}$ Foucault, Michel; Seguridad, territorio, Población. Curso del Collège de France (1977-1978); Fondo de Cultura Económica; Buenos Aires; 2006.

20

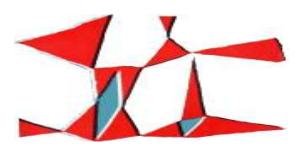

Anuario № 25, Escuela de Historia

Revista Digital № 4, Facultad de Humanidades y Artes, Universidad Nacional de Rosario, 2013

ISSN 1853-8835 
conceptos para articular una investigación ya terminada y publicada con el título: Tejidos Oníricos. Movilidad, capitalismo y biopolítica en Bogotá (1910-1930)².

\section{Movimiento y seguridad}

En sus lecciones del Collège de France correspondientes al año lectivo 1977-1978, Foucault se ocupa de mostrar cómo entre los siglos XVI y XVIII nace la idea de que la función del Estado es procurar la felicidad, la salvación y la prosperidad de los gobernados. Comienza a imponerse la idea de que el poder del soberano no aumenta en relación directa con la anexión de territorios sino mediante la conquista de la voluntad de los gobernados, lo cual supone una ruptura con concepciones anteriores que hacían del acto de matar y de conquistar la manifestación suprema del soberano. Foucault estudia las tecnologías a través de las cuales el Estado se ocupa de potenciar la vida de la población y de crear unas nuevas condiciones de existencia: se combaten las enfermedades y las hambrunas, se aumenta la esperanza de vida, se hacen inversiones en educación y en cuidados para la población trabajadora, etc.

Este cambio en la economía del poder se produce hacia finales del siglo XVIII con el advenimiento de los fisiócratas, quienes rompen con la idea mercantilista de que la sociedad debe ser "reglamentada" y ordenada por entero. Los fisiócratas muestran que la población no es un "dato básico" sino un conjunto de procesos $^{3}$ que varían todo el tiempo: con el clima, con el comercio, con las costumbres, etc. La práctica gubernamental no se orienta entonces a reglamentar estos procesos sino a gestionarlos. Estos escapan de la ley del soberano pues se revelan como fenómenos naturales que deben ser "dejados actuar" dentro de ciertos límites. No se trata de garantizar la obediencia del súbdito y su pasividad con respecto a la ley. En adelante, la cuestión pasa por crear unas condiciones que permitan la actividad de los súbditos dentro de ciertos límites aceptables.

En este contexto aparece el concepto "dispositivos de seguridad". Foucault afirma que la gestión gubernamental tiene "como blanco principal la población y como mecanismo esenciales los dispositivos de seguridad" $^{\prime 4}$. Es decir que a través de los dispositivos de seguridad será posible generar unas condiciones de

\footnotetext{
${ }^{2}$ Castro Gómez, Santiago; Tejidos oníricos. Movilidad, capitalismo y biopolítica en Bogotá (1910-1930); Editorial Pontificia Universidad Javeriana; Bogotá; 2009.

${ }^{3}$ Foucault, Michel; Territorio, seguridad y población; Ob. Cit.; p. 93.

${ }^{4}$ Ibidem; p. 35.
}

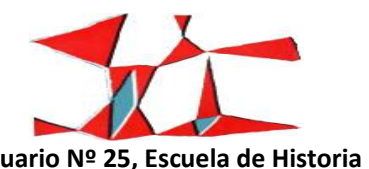


vida para la población que, además de aumentar las riquezas del Estado, permitirán defender a esa población de los riesgos de la muerte. Para Foucault, los dispositivos de seguridad están dotados de una racionalidad diferente a la de los dispositivos de soberanía y a los dispositivos disciplinarios. Los dispositivos de seguridad conllevan, pues, una ruptura con el modus operandi del poder soberano.

El gobierno sobre la salud, sobre la producción y la circulación son los tres fenómenos estudiados por Foucault para ejemplificar el funcionamiento de los dispositivos de seguridad ${ }^{5}$. Pero de estos tres ámbitos, enfermedad, escasez y movimiento, me concentraré sólo en el último. Foucault muestra cómo el texto La Métropolitée de Alexandre Le Maitre (1682) se inscribe en el surgimiento de esta problemática: ¿cómo gobernar un fenómeno natural llamado "movimiento"? Aunque inscrito todavía en el ámbito de la razón de Estado, el proyecto de La Maitre enseña que el problema que debe resolver una ciudad es el de la circulación ${ }^{6}$. El urbanismo procura gestionar la circulación en diversos niveles: circulación de enfermedades, circulación de clases peligrosas, circulación de mercancías, circulación de deseos. ${ }^{7}$ Pero además de promover la circulación permanente de todos estos fenómenos, los dispositivos de seguridad buscan proteger al ciudadano de los riesgos y peligros que conlleva tal circulación. Defender, pues, la ciudad de las "malas circulaciones", porque con el comienzo de la industrialización el "peligro social" ya no está en el campo (revueltas campesinas) sino en la ciudad: levantamientos de la plebe en proceso de proletarización.

Con todo, los dispositivos de seguridad no buscan prohibir la circulación, haciendo que todas las cosas se queden en su lugar (ciudad soberana), sino producir una movilidad y gestionarla eficazmente (ciudad securitaria). La naciente economía política muestra que no es posible ni deseable evitar la existencia de malas circulaciones, pero sí la necesidad de gestionarlas. En la ciudad habrá enfermedades, clases peligrosas, comercio indeseado y deseos lícitos, pero de lo que se trata ahora es de normalizar esta multiplicidad de circulaciones a través del gobierno. $Y$ "gobernar" significa en este caso, gestionar el movimiento en función de un cálculo de probabilidades ${ }^{8}$. En lugar de imponer a los cuerpos una ley que los deje "quietos en su lugar", los dispositivos de seguridad crean un espacio urbano en el que estos cuerpos

\footnotetext{
${ }^{5}$ Ibídem; p. 87.

${ }^{6}$ Ibídem; p. 32.

${ }^{7}$ Ibídem; p. 38.

${ }^{8}$ Ibídem; pp. 39-49.
}

22

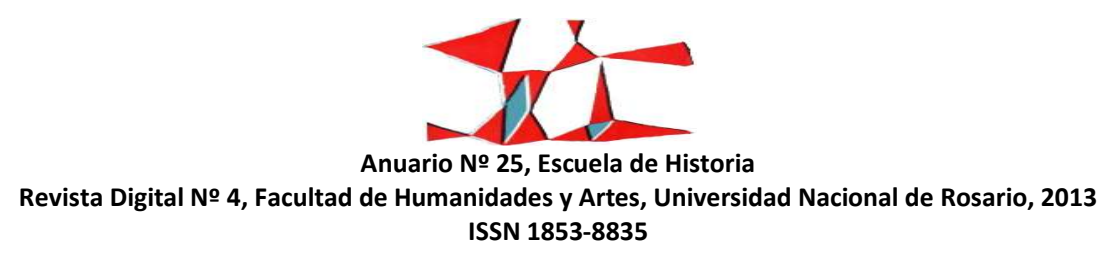


puedan moverse continuamente. En lugar de disciplinarlos, producen artificialmente un escenario de cinesis.

¿Por qué razón se busca convertir la ciudad en un espacio de cinesis permanente? Foucault dice que los dispositivos de seguridad ya no buscan el "simple vivir" de las personas, sino el "más que vivir" que su función es producir una vida cualificada, una vida de bienestar, una vida feliz y confortable, pero siempre en concordancia con los objetivos gubernamentales del Estado. No se trata ya de que la población sobreviva y ni siquiera de que "viva bien", sino de que viva mejor y siempre mejor. O, por lo menos, como lo mostraré en la segunda parte de este trabajo, de que albergue la ilusión de que es posible vivir siempre mejor.

A continuación quisiera distinguir cuatro características de los dispositivos de seguridad y analizarlas desde el punto de vista del gobierno sobre el movimiento, es decir de la movilidad urbana.

1. Los dispositivos de seguridad insertan los fenómenos "dentro de una serie de acontecimientos probables $^{\prime 10}$, es decir que se mueven en el campo de las probabilidades. Ya no se trata de sancionar leyes contra los movimientos indeseados (como hacen los dispositivos jurídicos) ni tampoco de corregir a los que se mueven más allá de los límites legales (como hacen los dispositivos disciplinarios) sino de gestionar la movilidad urbana dentro de un intervalo posible ${ }^{11}$. Los dispositivos de seguridad operan mediante el cálculo de riesgos y de $\operatorname{costos}^{12}$. No se trata, pues, de impedir el movimiento sino de convertirlo en movilidad, de potenciarlo y gestionar sus riesgos. Mantener esa movilidad dentro de un intervalo aceptable, de manera que no suponga una amenaza para la estabilidad del gobierno y tampoco para el conjunto de la población. Los dispositivos de seguridad no intentan impedir la naturalidad del "movimiento", sino dejar que ese acontecimiento se manifieste y regularlo en términos de movilidad urbana. No actúan conforme al eje soberano-súbditos, sino conforme al eje gobierno-población, por lo cual no adoptan la forma de una vigilancia exhaustiva sobre el movimiento de los cuerpos, sino procura que estos circulen y se movilicen.

\footnotetext{
${ }^{9}$ Ibídem; p. 376.

${ }^{10}$ Ibídem; p. 21.

${ }^{11}$ Ibídem; p. 21.

${ }^{12}$ Ibídem; p. 29.
} 
2. Los dispositivos de seguridad actúan mediante la producción de un medio (mileu). "Fabrican" un medio artificial que favorezca la cinesis permanente. Ese medio es producido a través de un conjunto de procedimientos técnicos: estadísticas, formas arquitectónicas, planeación urbana, intervenciones higiénicas sobre la ciudad, etc. Su objetivo es "afectar una población"13, cambiar y "mejorar" sus condiciones de vida, con el fin de potenciar el aumento de riquezas. Pero los dispositivos de seguridad operan mediante la “acción a distancia" ${ }^{14}$, es decir que no intervienen directamente sobre los cuerpos sino sobre el medio en el que los cuerpos existen. No buscan modificar directamente la conducta, sino las "condiciones de la conducta". Se trata de la afectación de una población mediante la producción artificial de un medio.

3. Los dispositivos de seguridad no buscan disciplinar los deseos sino ponerlos a circular. No se prohíbe la circulación del deseo pero se le marcan unas trayectorias, unos recorridos, unos objetos. En lugar de represión, se propone el estriamiento del deseo. Foucault muestra que el nacimiento de la economía política conlleva el reconocimiento de la dimensión productiva del deseo. Los fisiócratas son los primeros en mostrar que el deseo impulsa todas las acciones de los individuos y que "contra él no se puede hacer nada" ${ }^{15}$. No se trata ya de reprimir el deseo (ejecutando a los transgresores de la ley moral) ni de cambiarlo (encerrando a los que han perseguido sus deseos de forma prohibida) sino de gobernarlo, de gestionarlo. Hay que dejar actuar el deseo de las personas, pero dentro de ciertos límites, pues en última instancia, si cada cual persigue sus deseos esto redundará en beneficio económico de la colectividad. Cada cual debe buscar su propio interés, perseguir sus propios deseos. De lo que se trata es de dejar actuar el juego espontáneo de los deseos, gestionando sus condiciones de circulación. Para los fisiócratas y luego para los liberales, el problema ya no será la represión sino la permisión el deseo, como "decir sí" al deseo ${ }^{16}$, cómo lograr que la circulación social del deseo produzca beneficios para la población que se quiere gobernar. Pues gobernar no significa reglamentar a partir del derecho, sino decidir pragmáticamente qué es útil o qué es inútil hacer. El problema es, entonces, la utilidad del deseo, su capacidad de generar riqueza pública. No se trata, pues, de intervenir sobre el deseo en sí mismo sino de gestionar su movimiento en el ámbito de la ciudad.

\footnotetext{
${ }^{13}$ Ibídem; p. 41.

${ }^{14}$ Ibídem; p. 40.

${ }^{15}$ Ibídem; p. 96.

${ }^{16}$ Ibidem; p. 97.
}

24

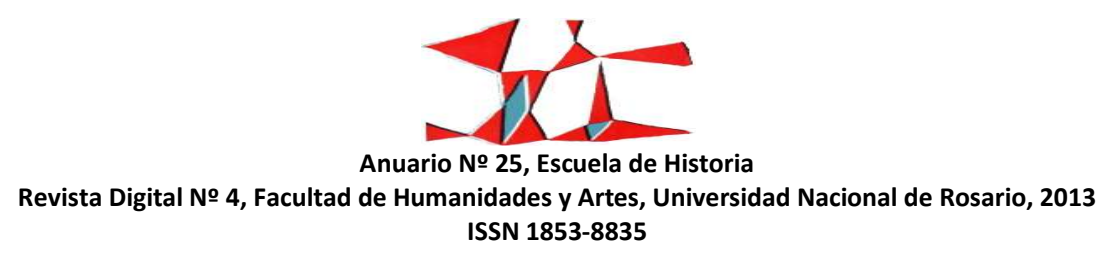


4. Los dispositivos de seguridad operan mediante la producción de un público, de una esfera de actuación en la que los individuos se mueven, persiguen sus intereses y escenifican sus deseos. En su clase del 25 de enero de 1978, Foucault dice que el público es la población considerada desde el punto de vista de sus intereses, sus deseos y sus opiniones ${ }^{17}$. El gobierno de la población conlleva entonces la gestión de los públicos. Ya en la clase del 15 de marzo, Foucault había dicho que el problema del soberano era cómo imponer una opinión, una representación al público, de tal manera que éste pudiera reconocerse en ella ${ }^{18}$. El público aparece en el marco de la razón de Estado pero como un público espectador, que contempla la teatralización del poder hecha por el soberano ${ }^{19}$. Sin embargo, el público que empieza a surgir de la mano de los dispositivos de seguridad ya no es un público espectador sino un público actor y productor de sus propias representaciones. Es un público que no se reconoce ya en la autorepresentación teatral del soberano sino en la escenificación de sus propios deseos. El gobierno sobre la población requiere ahora de ciudadanos libres, capaces de autoproducirse.

\section{El dispositivo de movilidad en Bogotá}

Trataré de mostrar ahora cómo las herramientas fabricadas por Foucault, arriba mencionadas, pudieran resultar útiles para pensar el tema de la movilidad urbana en una ciudad como Bogotá hacia comienzos del siglo XX. Pero quisiera primero mostrarles brevemente de dónde proviene mi interés por investigar el tema de la movilidad y su relación con los procesos de industrialización.

Ya para el año de 1910, la revolución industrial había transformado sustancialmente la economía, la política y la cultura de los países que en aquel momento se disputaban la hegemonía del mundo. Gran Bretaña, Francia, Estados Unidos y Alemania eran las cuatro naciones que habían logrado incorporar los recientes adelantos tecnológicos y científicos en la producción capitalista de bienes y servicios, mientras que los demás países de la periferia europea y todas las regiones de la periferia colonial, permanecían ancladas en un modo pre-industrial o semi-industrial de producción, centrado en la agricultura y la exportación de materias primas a los centros. Gran Bretaña había detentado la hegemonía del sistema mundial durante buena parte del siglo XIX gracias a su rol pionero en la llamada "primera revolución

\footnotetext{
${ }^{17}$ Ibídem; p. 102.

${ }^{18}$ Ibídem; p. 125.

${ }^{19}$ Ibídem; pp. 308, 323.
} 
industrial", pero hacia finales del mismo parecía claro que los Estados Unidos se perfilaban como la nueva potencia económica mundial, dejando a atrás a sus más inmediatos rivales, Francia y Alemania. Los ferrocarriles, el telégrafo, la electricidad, los automóviles, empiezan a convertirse así en elementos claves para el flujo rápido de la mercancía, lo cual abarataría los costos de su producción y permitiría la conquista de nuevos mercados. La habilidad de producir y transportar mercancía para ubicarla con rapidez en lugares distantes conllevaría también el desarrollo de un nuevo modelo organizativo, centrado ya no en la empresa familiar o local, sino en un tipo de empresa corporativa capaz de operar en diferentes lugares y de ejercer diversas funciones. Todo debía moverse, circular, desplazarse. No solamente el dinero y los objetos, sino también los cuerpos, las ideas y los hábitos tenían que moverse, so pena de quedar "retrasados" en el creciente movimiento universal hacia el progreso.

De la industrialización me interesa, entonces, un factor que por lo general no es tenido muy en cuenta por historiadores, economistas y sociólogos: la movilidad. Para ser más exacto, me interesa investigar cómo hacia la década de 1920 empieza a implementarse en Colombia un imaginario social centrado en la velocidad y la aceleración permanente de la vida. Pues "industrializarse" significaba no solamente que el dinero y los objetos, sino también las naciones, las personas, las ideas y los hábitos tenían que moverse con velocidad, para conseguir articularse al incremento de la movilidad universal orientada por el progreso. Mi hipótesis es que la industrialización del país demandaba una nueva relación de las personas con el movimiento, la emergencia de unas subjetividades cinéticas capaces de hacer realidad el orden social imaginado -pero no realizado- por las elites liberales del siglo XIX. Para que Colombia pudiera ingresar con éxito a la dinámica industrial del capitalismo mundial, los cuerpos debían adquirir una nueva velocidad. Había que producir un nuevo tipo de sujeto desligado de su tradicional fijación a códigos y hábitos mentales preindustriales, y esto conllevaba la necesidad de implementar una serie de dispositivos que permitieran la rápida circulación de personas y mercancías.

Ya observamos cómo Foucault señala que las ciudades se convirtieron a partir del siglo XVIII en verdaderos campos de experimentación del biopoder; lugares donde debía producirse un "medio ambiente" (milieu) artificialmente creado (viviendas con condiciones higiénicas, calles pavimentadas, servicio de transporte urbano, acueducto y alcantarillado, zonas de recreación, etc.) con el fin de promover y controlar la circulación. Proteger a la población de enfermedades que disminuyan la potencia de sus 26

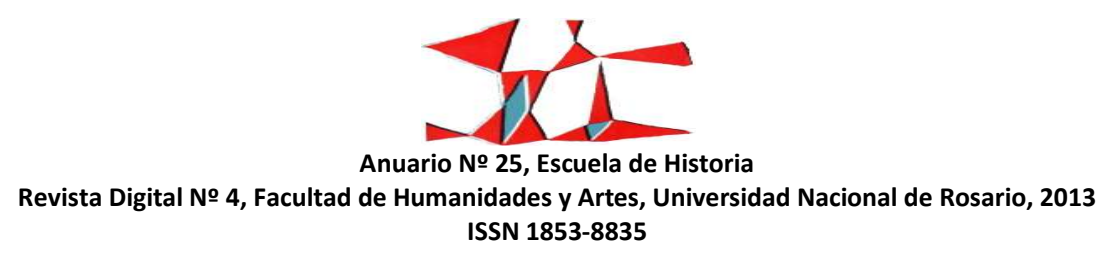


cuerpos, al mismo tiempo que favorecer la rápida circulación de mercancías y controlar la afluencia de "sujetos flotantes" (vagos, mendigos, delincuentes, prostitutas), son entonces las funciones que cumple la ciudad en un régimen de seguridad, condición indispensable para el asentamiento de la economía capitalista.

Y aunque fue ciertamente Medellín la primera ciudad colombiana que, gracias al boom de la economía cafetera, se convertiría en ese campo de experimentación biopolítica del que nos habla Foucault, ya desde 1910 Bogotá había empezado un significativo proceso de transformación urbana que merece atención. El modelo de ciudad al que aspiraban las elites industriales de la capital ya no era Atenas, ciudad estática y señorial, asiento de filósofos y poetas, como habían querido las elites letradas durante la segunda mitad del siglo XIX, sino Nueva York, lugar por excelencia de la circulación y el movimiento. Bogotá empieza a ser vista como una ciudad donde la cinesis permanente debía establecerse como un modo de vida, y esto no solo gracias al despliegue de los nuevos medios de transporte, sino también a las contribuciones del urbanismo, cuyo objetivo no era simplemente construir "cosas" en un medio ambiente ya preestablecido, sino construir ese medio ambiente. Por eso la nueva Bogotá no debía ser la simple ampliación de la vieja Santafé, sino otro "mundo de vida" completamente diferente. O para decirlo con mayor precisión: Bogotá debía ser una prótesis de mundo de vida. El urbanismo de aquellas décadas no buscaba solo construir edificios y grandes avenidas sino construir al ciudadano, producir al homo urbano en tanto que soporte indispensable para el advenimiento del homo economicus.

A continuación mostraré cómo las herramientas teóricas de Foucault han resultado útiles para investigar la implementación de una serie de mecanismos capaces de acelerar la vida de la población en Bogotá, permitiendo la rápida circulación de personas, ideas, mercancías y fuerza de trabajo. Analizaré, pues, el tema de la movilidad urbana en la Bogotá de comienzos de siglo considerando cuatro áreas problemáticas: 1) el city planning, 2) la semántica de los medios de transporte rápido, 3) el gobierno de las "malas razas" y 4) la movilización de afectos y deseos.

\section{1) El city planning}

Desde finales del siglo XIX, la visión de las elites modernizadoras era que las ciudades debían cambiar radicalmente su vieja estructura colonial. Una vida económica ligada orgánicamente a las dinámicas

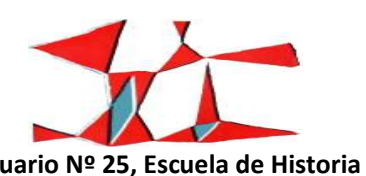


agropecuarias no podría servir al propósito general de vincular a Colombia en la cinesis permanente del mundo moderno. Para los festejos del Centenario en 1910, y con mayor fuerza durante los años subsiguientes, Bogotá ya había empezado a cambiar esa fisonomía colonial indeseada por las élites. El modelo de ciudad al que aspiraban no provenía del mundo clásico, aquel con el que identificaron sus deseos los letrados bogotanos durante la segunda mitad del siglo XIX, sino Nueva York el corazón del capitalismo de la circulación y el movimiento. El siguiente hecho quizás nos sirva como símbolo de este cambio. El día 6 de noviembre de 1923, el ex presidente de Colombia Marco Fidel Suárez, un "humanista" en la tradición decimonónica de Caro y Cuervo, caminaba en medio de la calle 12, abstraído quizás en la preparación de sus Sueños de Luciano Pulgar, cuando un pesado camión le atropelló de forma aparatosa. El accidente no trajo al parecer mayores consecuencias para Suárez, pero sí era un claro indicador de que el espacio-tiempo de los gramáticos, aquella República de las letras preindustrial y aldeana, en la que las personas nacían y morían con las mismas codificaciones territoriales, se encontraba herida de muerte. En su lugar estaba emergiendo un nuevo mundo, tecnológicamente producido, en el que las relaciones sociales estaban siendo mediadas por el dinero y por la velocidad de su circulación.

Durante las primeras décadas del siglo XX se inicia la construcción de un nuevo universo urbano para Bogotá, muy diferente de aquel que caracterizaba a la ciudad colonial y decimonónica. El mejoramiento de las vías de transporte, la electrificación de las calles y la creación de una infraestructura orientada hacia el consumo debía favorecer el carácter productivo de la ciudad y la emergencia de nuevos roles ocupacionales. Pero la formación de este nuevo universo urbano no podía ser dejada al azar, sino que debía ser efecto de la planificación. Lo que aparece, pues, durante las dos primeras décadas en Bogotá es la pregunta de cómo gobernar a la población a través de criterios científico-técnicos que confluyen en un proyecto específico: el urbanismo. En febrero de 1917 el industrial antioqueño Ricardo Olano publica en Bogotá un artículo titulado "City Planning", en el que discute las nuevas ideas científicas sobre el urbanismo. Olano estaba ligado a la Sociedad de Mejoras Públicas de Medellín, primera ciudad del país que incorpora este debate, ampliamente conocido en Estados Unidos y Canadá desde comienzos de siglo. No hay que esperar pasivamente a ver qué nos trae el futuro, afirma Olano, pues el futuro no es cosa del azar sino del diseño. Si no se quiere que las ciudades colombianas crezcan de forma desordenada, es necesario planificar científicamente su crecimiento. Olano propone implementar un plan de desarrollo urbano que pueda ser

28

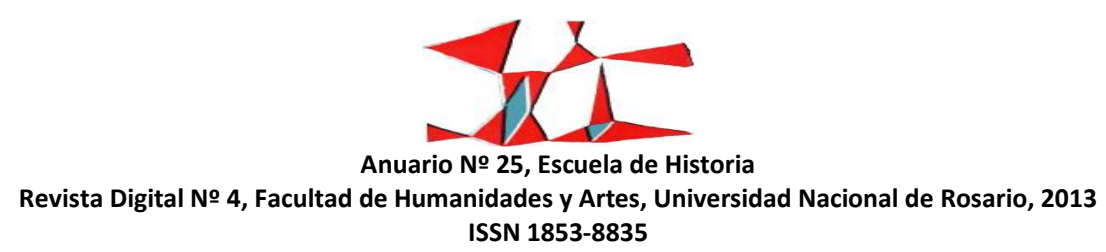


una ley obligatoria de la República para todas las ciudades del país, ya que sin el "levantamiento de su plano futuro", ninguna podrá brindar a sus habitantes "salud, confort y alegría".

Estética, confort, higiene y goce de vivir son entonces los nuevos ideales del urbanismo científico. El "plano de la ciudad futura" del que habla Olano buscaba, precisamente, sustituir las estrechas e irregulares calles de la ciudad colonial -sinónimo de caos y fealdad-por amplias y rectas avenidas que ofrecieran al ciudadano la sensación de orden y hermosura. Un ideal estético basado en la amplitud, en la sensación de caminar hacia el futuro que ofrece la línea recta, pues las calles irregulares y cortas suponen un obstáculo serio para la ventilación de los edificios, para el desagüe de las alcantarillas, para el movimiento rápido de las personas y, en general, para la hermosura de la ciudad. El City Planning quiere romper, entonces, con la "antigüedad" del trazado urbano colonial y sustituirlo por el nuevo trazado "científico" que se venía ensayando en países civilizados como Inglaterra. Las calles deben romper con ese riguroso trazado geométrico implantado por los españoles, pues la monotonía de las manzanas cuadradas y de las calles paralelas genera en el espíritu un sentimiento de apatía e inmovilidad. Ramblas arborizadas (también conocidas como park-ways), avenidas arteriales de tráfico, calles diseñadas para la implementación de agua y electricidad en todas las viviendas: tales fueron las propuestas que se discutieron en el Consejo de Bogotá entre 1920 y 1925 . El ideal de la circulación permanente debía ser introyectado por los bogotanos y para ello era necesario producir racionalmente un "medio ambiente" que lo favoreciera.

Quizás en ningún otro proyecto urbano de los años 1920s. se cumplió con más exactitud este triple programa de higienización, embellecimiento y movilidad como en la prolongación hacia el oriente de la Avenida Colón, que recibió el nombre de "Avenida Jiménez de Quesada". Con la construcción en 1925 de la Jiménez las autoridades esperaban resolver "científicamente" tres tipos de problemas. El primero era un problema de higienización y tenía que ver con el saneamiento (idefinitivo!) del río San Francisco, pues sus aguas arrastraban desechos provenientes de los cerros orientales (donde se ubicaba el tristemente famoso Paseo Bolívar), lo cual provocaba malos olores y potenciales focos de infección, justo en una zona estratégica para el desarrollo de la ciudad. Hacer que las aguas circulen, que el aire pestilente circule, que las enfermedades circulen. El segundo era un problema de embellecimiento y tenía que ver con la imagen moderna que se le quería imprimir a la ciudad. La avenida Jiménez debía convertirse en el corazón financiero de la ciudad; en una especie de "Wall Street colombiano" donde se construirían imponentes

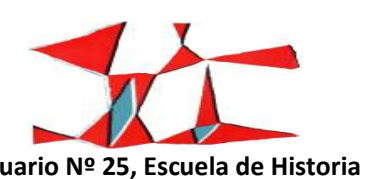


monumentos a la Banca como el edificio López de tres pisos y el edificio Cubillos de ocho pisos, este último dotado de ascensor. Todo ello debía generar tanto en los habitantes de la ciudad como en los inversionistas extranjeros, la fantasmagoría de una ciudad moderna y civilizada, a tono con la exigencia de los tiempos. Circulación, pues, de afectos, deseos y sensaciones estéticas. El tercer problema que buscaba resolver la construcción de la avenida Jiménez era un asunto de movilidad y tenía que ver con la integración de los tres sistemas de transporte vigentes en aquella época: el ferrocarril, el automóvil y el tranvía. Al ser una prolongación de la avenida Colón, la Jiménez representaba el punto de unión entre el centro financiero de la ciudad y la Estación de la Sabana, a la cual se podría acceder tanto por automóvil como por tranvía. De este modo sería posible convertir el antes aislado sector de la Estación de la Sabana en un importante polo de desarrollo económico mediante la construcción de hoteles para viajeros, grandes almacenes y erección de obras públicas como los hospitales de San José y La Misericordia. Interconexión rápida, movilidad, adecuación de los espacios de la ciudad para convertirlos en espacios para la generación de una cinética urbana.

\section{2) La semántica de los medios de transporte rápido}

La revolución de la velocidad empezó a generar en Bogotá una nueva forma de significar el mundo que va de la mano con los cambios en las formas de habitar la ciudad. Esto quiere decir que en el momento en que las máquinas industriales entran a formar parte integral del paisaje urbano, estas formas de habitar la ciudad cambian por completo.

Uno de los mayores cambios en la significación del espacio urbano introducidos por el transporte rápido durante las primeras décadas del siglo XX tiene que ver con la experiencia de la temporalidad. Recorrer la ciudad de forma veloz empezó a convertirse para los bogotanos en una experiencia "natural", en la medida en que se popularizaron medios de transporte como el automóvil y el tranvía. En 1892 salía un tranvía a Chapinero cada 20 minutos, en 1895 cada 10 minutos y en la década de los veinte, con el tranvía ya electrificado, el viaje completo no duraba más de quince minutos. Tan "normal" se fue convirtiendo la frecuencia y velocidad de estos recorridos $-\mathrm{y}$ tan estructural para el funcionamiento de la ciudad- que cuando el tranvía se retrasaba por algún motivo, la gente protestaba con indignación. Ya nadie parecía recordar que, pocas décadas antes, la experiencia "normal" de la temporalidad urbana estaba relacionada

30

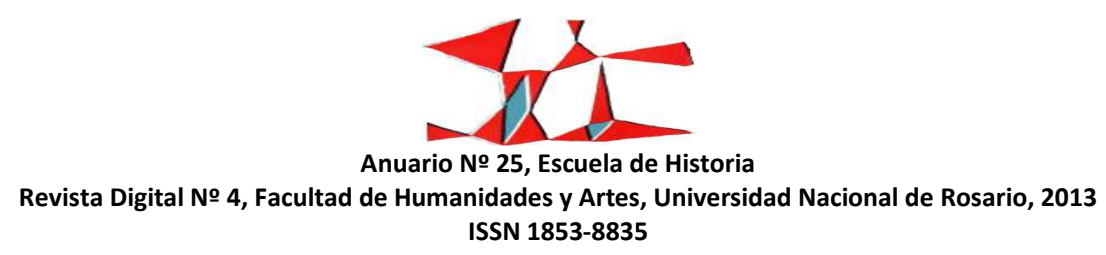


con los recorridos a pié. El tiempo de la vida (personal, familiar, laboral) empieza a depender entonces de la rapidez de los desplazamientos mecánicos. Según datos ofrecidos por la Fundación Misión Colombia, a comienzos de los años 1920s. circulaban en Bogotá, además del tranvía, 218 automóviles, 155 coches de caballo, 218 carros de resorte, 866 bicicletas, 60 motos, 46 camiones, y para 1925 el número de automóviles había subido a 1.070 y el de camiones a 375. Y la presencia de estas máquinas generó cambios en la manera en que las personas percibían el espacio urbano y se percibían a sí mismas.

Quizás fue el automóvil la máquina industrial que mayor impacto provocó en el imaginario de los bogotanos, a pesar de que su precio (alrededor de 1.500 pesos para 1925) se encontraba fuera del alcance de la mayoría de la gente. Pero más que un medio de transporte (es decir más allá de su "valor de uso"), el automóvil arrastraba un valor simbólico importante. Era emblema del tipo de sujeto que la modernidad industrial necesitaba crear en el país: el sujeto como "conductor", como ser capaz de someter sus pasiones al control racional, de darse su propia ley (auto-nomos) y de moverse a partir de sus propias fuerzas (automobile). El automóvil otorga al individuo una identidad específica: la del sujeto que es libre para moverse hacia donde quiera y a la hora que quiera, sin depender para ello de la voluntad de otro. Con la introducción del automóvil en Bogotá, el ideal del movimiento del sujeto a partir de sí mismo parecía encontrar su cumplimiento. El automóvil es la metáfora perfecta del sujeto que la industrialización necesitaba: el individuo aislado del exterior por un ensamblaje tecnológico que le sirve de "casa", en donde puede y debe tener un control absoluto sobre todos sus movimientos. Ningún otro objeto representó de forma más plena la utopía cinética del capitalismo industrial: la auto-movilización. Por eso la publicidad de automóviles buscó siempre vincular dos elementos inseparables de esa utopía: actividad e independencia. Ser sujetos modernos significa ser capaces de generar movimiento a partir de las propias fuerzas y en la dirección que uno quiera. De ahí que las primeras campañas publicitarias de carros en Bogotá hicieran énfasis en la libertad de poder salir a cualquier lugar y a cualquier hora, sin necesidad de depender de los horarios fijos de trenes y tranvías. La subjetividad entendida, pues, como voluntad de movilización permanente, como perpetuum mobile.

De otro lado, hacia finales de los años veinte, cuando la ciudad contaba con algo más de mil automóviles para una población total de 224.000 habitantes, el espacio urbano empezó a ser transformado en un medio para la circulación. Cuando la ciudad empezó a ser reorganizada según los nuevos imperativos

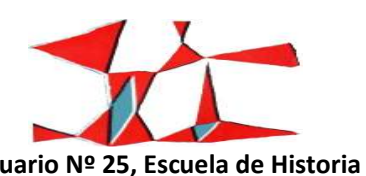


de la velocidad, se convirtió en un "mundo" muy diferente al que habían conocido los bogotanos del siglo XIX. Las calles dejaron de ser el lugar de reunión de las personas, el ámbito donde se comunicaban los acontecimientos y chismes cotidianos o donde se podía caminar distraídamente y sin afanes (como lo hacía Marco Fidel Suárez), para convertirse en calzadas destinadas al tránsito rápido de peatones y a la circulación de los carros. Ya desde el año 1905 empezaron a construirse en Bogotá los primeros andenes, que disminuían en más de un $70 \%$ el espacio por el que podía caminar la gente, acostumbrada hasta entonces a disponer de toda la calzada. El andén -que por aquel entonces tenía una anchura promedio de 1,50 metros- no solo concedía prioridad a la velocidad del automóvil sobre la velocidad del peatón, sino que obligaba a una circulación mucho más rápida de estos, que ahora se veían abocados a caminar ligero en medio de la aglomeración y del comercio. Con la adecuación de los andenes a comienzos del siglo XX, las calles de Bogotá dejaron de ser un espacio donde simplemente "hay" mercancías, para convertirse en espacios donde la mercancía se encuentra en circulación permanente.

\section{3) El gobierno de las "malas razas"}

La movilidad que se promueve en Bogotá desde comienzos de los años 1920s. no debía ser sólo para la incipiente burguesía industrial, sino también para la naciente clase obrera. Ambos sectores echaban sus raíces en las antiguas estructuras socioeconómicas de la colonia y la República, pero ahora se articulan a una naciente formación capitalista-industrial de carácter urbano. La emergencia de la clase obrera

planteaba entonces una serie de preguntas para las elites: ¿qué hacer con la creciente visibilidad y movilidad de estos sectores populares, vistos como inferiores tanto social como racialmente? ¿En qué punto del universo urbano tenían que ubicarse? ¿Cuál debía ser su participación en la nueva infraestructura de bienes y servicios? ¿Cómo generar dispositivos capaces de movilizar sus cuerpos y sus mentes? Y en caso de fracasar estos dispositivos, ¿cómo crear mecanismos de seguridad capaces de contener los vicios, enfermedades y desviaciones que trae consigo esta población inmóvil?

La creación de espacios artificiales, adecuados para la movilización de los cuerpos trabajadores, fue una de las soluciones más adecuadas. Al igual que los edificios y almacenes de mercancías, las fábricas debían ser espacios en los que al mismo tiempo que se fomentaba la producción industrial, se interpelaba también a los trabajadores para convertirlos en "obreros", es decir en sujetos modernos. La higiene y la

\section{2}

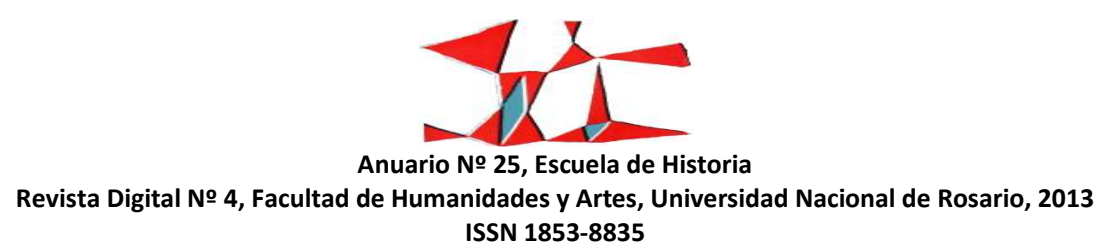


racionalidad de los espacios de trabajo eran requisitos para la construcción de fábricas al interior de la ciudad y para la aprobación de sus licencias de funcionamiento. La producción de un ambiente higiénico y funcional en medio de la ciudad, tal como el que debía reinar en las fábricas, cumple una importante misión pedagógica ya que debía servir como medio para suavizar las bárbaras costumbres de la plebe. De este modo, la fábrica, con su rigurosa disciplina corporal del trabajo y las condiciones higiénicas en que se desarrolla el mismo, es un medio ambiente artificial capaz de producir un tipo específico de subjetividad cinética, purificada ya de todos los vicios coloniales: el obrero. El ambiente artificial de la fábrica y su aislamiento espacial con respecto al mundo tradicional que la rodea, sirve entonces como metáfora de lo que significa ser un sujeto moderno: alguien que vive en esferas tecnológicamente producidas y que ha roto sus vínculos con el mundo rural no capitalista, el mundo de la producción artesanal, que ahora es visto como perteneciente al "pasado de la humanidad"; alguien que, además, ha logrado incorporar en su mente y en su cuerpo los ritmos maquinales de la producción, hasta el punto de convertirse en parte fundamental de su engranaje.

La construcción de barrios obreros fue otra de las estrategias para la creación de ambientes artificiales en Bogotá, capaces de promover el movimiento de las clases subalternas. Aunque los primeros barrios obreros de Bogotá se crearon en el emblemático año de 1910 por parte de la Sociedad Católica de San Vicente de Paul, el proyecto piloto fue el desarrollado por los padres jesuitas en el barrio de San Francisco Javier, al sur de la ciudad, a medio camino entre Las Cruces y San Cristóbal, dirigido por el sacerdote José María Campoamor. "Villa Javier" era el nombre con que se conocía el terreno donde estaban construidas cuarenta o cincuenta casas para obreros, en un lugar rodeado de árboles y flores, que buscaba crear un ambiente adecuado para la producción de la subjetividad obrera. En Villa Javier se construyeron casas que cumplían con los mismos imperativos que guiaron la construcción tanto de los edificios de la Avenida Jiménez como la de las grandes mansiones burguesas de Chapinero y Teusaquillo: aire, higiene y luz.

En Villa Javier se enseñaba a los obreros las virtudes de un modo de vida ya propiamente moderno pero católico, centrado en la higiene, la moral, el ahorro y el trabajo, de modo que pudieran hacerlo suyo e identificarse vitalmente con él. La vida pública debía centrarse en el trabajo productivo, mientras que la vida privada debía centrarse en la familia, bajo los parámetros cristianos enseñados por la Iglesia, y es por eso

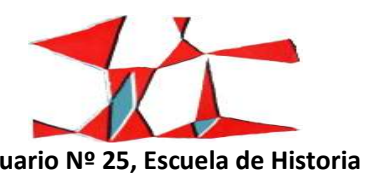


que el "lecho matrimonial" se ubicaba en el centro de la vivienda obrera. Había que asegurar no solo que el cuerpo del obrero pudiera vigorizarse a través de unas condiciones saludables e higiénicas y que su alma se viera libre de toda desviación moral, sino también de que no malgastara sus ingresos. Por eso en Villa Javier era importante inculcar en los obreros el hábito del ahorro. El obrero tenía que aprender a utilizar racionalmente no solo su tiempo (en la fábrica y en el hogar) sino también su dinero, de tal modo que pudiera disponer de ahorros suficientes en caso de quedar desocupado, con el fin de sostenerse mientras vuelve a encontrar trabajo. De este modo, el tiempo de la vida del obrero, no solo el que pasaba en la fábrica sino el tiempo de su vida entera, debía ser utilizado de la mejor forma posible al servicio del aparato de producción. Es así como a través de una institución de beneficencia cristiana como Villa Javier, encaminada a ofrecer seguridad y protección a los menos favorecidos, se establece un mecanismo de gobierno tendiente a colocar todo el tiempo de la existencia obrera a disposición de los ritmos veloces del trabajo, bajo la supervisión moral de la Iglesia.

Este proyecto de reubicación a nivel espacial y de reidentificación a nivel de la subjetividad generó una actividad constructora sin precedentes (como también una gran especulación por parte de los urbanizadores), ya que la empresa privada y el Estado comenzaron a adquirir grandes extensiones de tierras, sobre todo en el sur de la ciudad, para luego ofrecer planes de autoconstrucción de vivienda para los obreros, otorgándoles créditos a largo plazo y bajo interés. Así por ejemplo, el barrio Unión Obrera (mejor conocido como "La Perseverancia") surgió patrocinado por la Cervecería Bavaria y otros proyectos de vivienda obrera surgieron en sectores como el Ricaurte, Córdoba, 20 de Julio, Primero de Mayo, Buenos Aires, Las Cruces y San Cristóbal. Todos estos barrios tenían como objetivo producir un medio ambiente urbano en el que los trabajadores pudieran sentirse parte del proyecto de industrialización, haciendo suyos los objetivos de la biopolítica estatal. Debían ser espacios higiénicos, educativos, funcionales, amplios y rápidamente conectados con el centro de la ciudad mediante un servicio permanente de tranvía y autobuses. El imaginario estatal-que pocas veces se tradujo a la realidad-era que todos los barrios obreros estuvieran equipados con servicio de acueducto y alcantarillado y que las viviendas se encontraran rodeadas de un ambiente campestre, como era el caso del terreno perteneciente al empresario Nemesio Camacho en inmediaciones del río Fucha, que luego formaría parte integral del barrio San Cristóbal. Se

34

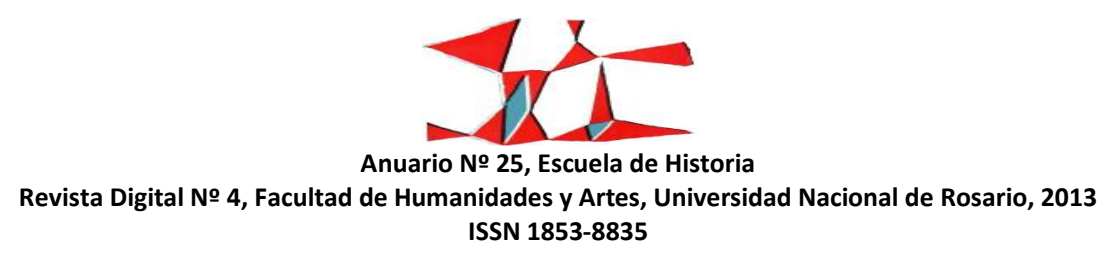


trataba, entonces, de producir subjetividades obreras construyendo y diseñando ambientes cinéticos en el sur de la ciudad.

\section{4) La movilización de afectos y deseos}

Afirmábamos antes, refiriéndonos a Foucault, que los dispositivos de seguridad no buscan disciplinar los deseos sino ponerlos a circular. La generación de espacios adecuados para la movilidad urbana arrastran un imperativo gubernamental: decir "si" a los deseos en lugar de reprimirlos; pero, al mismo tiempo, ejercer una modulación sobre esos deseos, de tal manera que puedan ser integrados al ámbito de la naciente sociedad del trabajo. Esto es justo lo que ocurre con la irrupción de la publicidad en Bogotá a comienzos de los años veinte. La publicidad es una tecnología que busca afectar las maneras de sentir con el fin de movilizar las maneras de vivir. Es un gobierno sobre los estilos de vida.

En los Estados Unidos, la publicidad nace a comienzos del siglo XX como una estrategia de ventas muy ligada al desarrollo de la psicología funcionalista. Los padres fundadores de la publicidad americana buscaron sustentar sus técnicas de persuasión en un estudio científico de la "naturaleza humana", tal como era propuesto en ese momento por los trabajos de J. B. Watson. Su preocupación era la de establecer la publicidad como una "ciencia del comercio", capaz de organizar y racionalizar las estrategias de control sobre el mercado. Fue así como la publicidad empezó a imponer su presencia en periódicos, revistas, avisos en la calle, litografías e impresos de todo tipo, hasta convertirse en una industria por sí misma. El publicista deviene un profesional especializado en la creación de mundos capaces de movilizar la sensibilidad del consumidor. Para lograr esto, no eran tanto las cualidades del producto lo que se promocionaba (precio, utilidad, valor de uso), cuanto el mundo asociado a esas cualidades (amor, fama, belleza, juventud, reconocimiento social).

La publicidad se hace sentir con fuerza en Bogotá hacia comienzos de la década de de la década de 1920, impulsada por la expansión imperial de las industrias estadounidenses en América Latina. Las cinco ramas de la industria americana que más dinero invertían en publicidad (cosméticos, alimentos, drogas, automóviles y tabaco) se hicieron presentes en diarios como El Tiempo y El Nuevo Tiempo, o en revistas como Cromos y Universidad. Si consideramos, por ejemplo, la publicidad vinculada con la industria médica y cosmética, él énfasis se desplaza desde las intervenciones planificadas sobre el espacio público a fin de

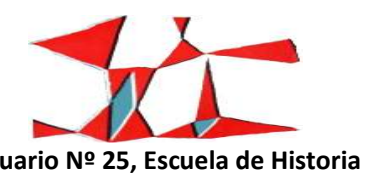


evitar el riesgo de propagación de tales enfermedades, hacia las intervenciones médicas y estéticas sobre el propio cuerpo. Intervenciones que ya no pueden verse como un efecto de las "disciplinas" descritas por Foucault (puesto que aquí no se trata ya de someter el cuerpo a determinados hábitos inducidos por la racionalidad de instituciones como la fábrica, el hospital, el cuartel general, etc.), sino como la autoinscripción del cuerpo en un "mundo", en un sistema estético de representaciones generado por los publicistas. Estamos, pues, frente una a tecnología de gobierno cuyo objetivo es movilizar los afectos, sentimientos, atención, deseos y memoria de los individuos, con el fin de crear un "público". Se gobierna la conducta de otros pero no directamente, sino mediante la producción de un "mundo" en el que esos otros pueden reconocerse y movilizarse. Un mundo en el que habita gente bella, exitosa, saludable, pues sin salud corporal y sex appeal es imposible cumplir las expectativas de la vita activa que demanda la industrialización.

La publicidad que se empieza a imponer en Bogotá durante la década de los veinte no hace referencia a remedios caseros o inscritos en un sistema tradicional de representaciones, sino a medicamentos desterritorializados, es decir a mercancías generadas por el discurso experto de la química, producidas en herméticos laboratorios y gerenciadas empresarialmente a través de modernas estrategias de marketing. La ciencia es vendida como el mejor aliado del individuo en su tenaz lucha contra la enfermedad y la fealdad. Este es un motivo repetido hasta la saciedad por la publicidad de los diarios capitalinos, que anuncia todo tipo de tónicos, píldoras, cremas, polvos, aguas y tabletas que prometen belleza y sanación eficaz. Dependerá de cada quien dotar al cuerpo con aquellos suplementos científicamente preparados que le hacen falta por naturaleza. Si alguien carece de vitaminas, de hierro, o de cualquier otro elemento natural que le impida tener una vida productiva, ahí están los medicamentos que la modernidad ofrece para suplir esta carencia. Y si alguien no ha tenido la suerte de nacer bello o bella, no importa. Ahí están toda una serie de productos que pueden mejorar o suplementar la dotación biológica: manos, pies, rostro, cabello y dentadura. Para construir una imagen estética de sí mismos, los individuos no necesitan tanto de la belleza natural sino del know-how. Y aquellos que no dispongan de este conocimiento están condenados a tener caspa, mal aliento, caries, piojos, arrugas, lagañas y resequedad en la piel. La enfermedad y la fealdad ya no son entonces asuntos de la naturaleza sino de la ignorancia. Estar enfermos o tener mala apariencia es un asunto de descuido, de irresponsabilidad consigo mismo, de negligencia para

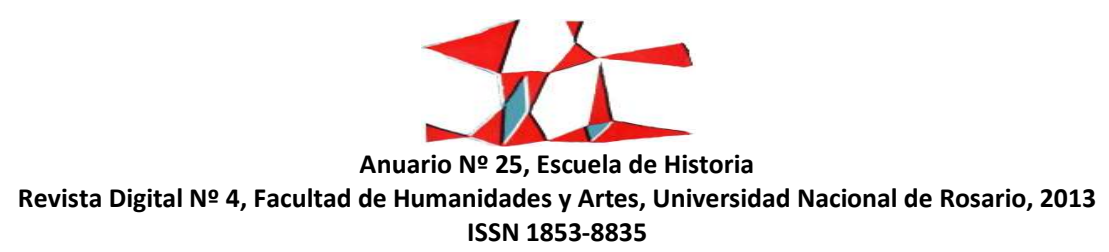


tomar el destino en las propias manos. El hombre y la mujer modernos, por el contrario, hacen de su propio cuerpo un objeto de manipulación técnica y deciden por sí mismos cómo quieren verse. Tecnologías del yo, pero inscritas plenamente en un dispositivo de movilidad que busca vincular el deseo de los individuos a la sociedad del trabajo.

Al considerar estas cuatro áreas problemáticas, no he querido agotar todos los temas abordados en Tejidos Oníricos, sino mencionar solo aquellos que guardan relación con las herramientas presentadas por Foucault en su curso Seguridad, Territorio, Población. No es Foucault tampoco el único referente teórico que utilizo, pero sí el que con más fuerza marcó mi trabajo investigativo durante los últimos años. Que sea este un motivo para conmemorar los casi treinta años de su muerte.

Recibido: 20 de junio de 2013 Aprobado: 30 de agosto de 2013 Versión final: 28 de octubre de 2013 